\title{
Type 2 Diabetes Mobile Application for Supporting for Clinical Treatment: Case Development Report
}

\author{
Thinnukool, $\left.\mathrm{O}^{(}\right)$, Khuwuthyakorn, P., Wientong, P., \\ Suksati, B., and Waisayanand, N \\ Chiang Mai University, Chiang Mai, Thailand \\ https://doi.org/10.3991/ijoe.v15i02.9769
}

\begin{abstract}
As clinical treatments for type-2 diabetes patients using mobile application on smartphones have become more widely practiced, the technology has enabled patients to easily control and monitor their blood sugar levels themselves. Although, the technology development provides more options to improve type- 2 diabetes treatment, not all applications developed are suitable for the real treatment as there might be different situations and treatments for different cases.

Research questions occurred while attempting to develop a diabetes mobile application as a supportive learning and self-monitoring tool. These research questions are the followings: How are patients enabled to use the diabetes mobile application effectively? And what are necessary functions of the mobile application for diabetes? The objective of this research are (1) to analysis, design, and development of a type-2 diabetes mobile application (T2DM) (2) to test the application.

The method starts with collecting users' requirements from diabetes experts, type- 2 diabetes patients and their relatives for using the type- 2 diabetes literacylearning tool. Five qualified diabetes experts and five pairs of diabetes patients with their relatives were investigated for gathering users' requirements that lead to necessary functions for the development. After the T2DM is completely developed, 18 medical staffs and 20 diabetes patients and patient relatives tested the T2DM by using the application.

Conclusion: When designing the more effective T2DM, developing of necessary functions by users' involvement ensures that requirements were analyzed and tested. It has been found that the nutrition function is the most significant piece of information for the T2DM, and also the key point of the development At the same time, the functions for blood sugar recording and information sending are the most supportive and helpful functions for users.
\end{abstract}

Keywords-Type-2 diabetes, mobile application, diabetes literacy learning tool, and diabetes self-management

\section{Introduction}

According to the World Health Organization, the number of diabetes patients has increased steadily from 108 million in 1980 to 422 million; this information was from 
200 countries and territories in 21 regions [1]. The harmful disease of diabetes can lead to many serious complications such as kidney disease, heart attack, blindness, and neuropathy. It has been projected to be the seventh leading cause of death in 2030 [1]. Moreover, diabetes requires more time for medical care and loss of much money for treatment. The majority of diabetics patients around the world are type 2 diabetes. There are several possible causes of the disease such as their bodies do not make enough insulin or become resistant to insulin or cannot use insulin properly. The research into the causes of type 2 diabetes is still ongoing. Since, the disease causes the blood sugar level to become too high, most type 2 diabetes patients need medication to keep their blood sugar level under control as normal as possible. Due to diabetes usually to get worse, medicine dose may need to change over time to find the right dose for each individual. Sometime, a combination of medicines may be required. Uncontrolled type 2 diabetes can lead to long-term high blood sugar levels, which can cause severe infections, slow-healing cuts, foot pain and/or feeling numbness in limbs. Without any treatment, type 2 diabetes can even become life threatening. As far as medication is concerned, unlike type 1 diabetes which only requires a strict protocol of daily insulin injections, type 2 diabetes requires complex treatment and medical care. Every individual with type 2 diabetes has to be treated with a different treatment plan because of the variations in patient habits, day-to-day life activities, genetic phenomena, ages, and stress condition [9]. Therefore, the difficulty of the complex treatment is that there is no exact procedure for medical treatment, because there are no daily indicators of glycemic control. To administer proper treatment to a patient, the doctor needs to find a suitable approach for short-term and long-term treatment plans.

Although, comprehensive medical evaluation by a doctor can improve diabetes disease care outcomes, an excellent component of diabetes treatment is patient selfmonitoring, together with cooperation between doctor and diabetes patient [4]. On the other hand, if the patient does not comply with doctor's recommendation, the result will be bound to the inadequate knowledge regarding the treatment, low selfconfidence, etc., which will lead to poor treatment outcomes in the view of the efforts to control the disease [3], [24], [25]. This would cause difficultly to the plan for effective medical treatment of patients with diabetes. Thus, cooperation between the doctor and the patient is the key to the success of the treatment.

The last century witnessed a doctor-patient cooperation model with the use of smart technology for assisting patient care [5]. At present, there has been great progress in the area of introduction of various smart tools in medication, which has increased ability to manage treatment plans and the likelihood of desired treatment outcomes [2][15]. Several application on smartphones are developed for helping patients and have been widely used for self-monitoring, providing medical suggestion, managing patients' health as self-management interventions, collecting real-time feedback and also being learning tool [6] [14] [16] [21]. Smart technology seems to be a wide- 
spread, accessible and affordable solution to enhance type 2 diabetes medical treatments in the doctor-patient cooperation way.

Some of the positive impacts of the technology to patients include improvement of the patient behavior patterns such as dietary activities, stress management and day-today life activities, enhancement of medical treatment knowledge and a doctor-patient cooperation treatment model. Moreover, there are several application functions have been developed and utilized to evaluate and recommend the next suitable treatment schedule from patient's data such as day-life activity records, blood glucose data, nutrition levels and comorbidities records, etc. [7][11]. The benefits of smart technology are clear for diabetes patients.

There have been more than 1,100 diabetes applications available in the app market, App Store and Google Play [17]. However, not many of them can provide support for real medical treatments while some of them may not be effective for all patients due to the limitation of the application usage, available languages and missed user requirements during requirements evaluation in the development process [11]. In addition, reports of several researchers state that millions of diabetes patients do not understand the information about the treatment or self-management education and never apply smart technology for any medical advice. Corresponding to the reports [18] and [19], in many commercial applications, there is a lack of evidence to support the recommendations of diabetes self-management through the apps. Developmental concerns have been focused on nutrition facts information that suits cultural food diversity, requirement-based functionalities and issues related to language barrier of Thai users. Thus, addressing the issue of developing a powerful application for the healthcare system or healthcare information technology is important before utilization of the application in the actual medical treatment.

Regarding to the diabetes application development, there are many points of features for providing necessary diabetes information need to be considered [2]. Firstly, collaboration between patient and doctor is an important point while designing the features, which is necessary for patient self-monitoring. In addition, there are various concerns about application usability, such as user acceptance, user satisfaction, system performance, and application encouragement, which are serious points to consider because mobile applications are different from other ordinary software [22].

Moreover, some recent reports have mentioned about a few studies which focused on the usability of the developed diabetes mobile applications ( 8 from 1,189 records) [12]. Usability test is important to investigate whether the application performs well or not and should be done first. Then, the application can be put to review or consider by doctors or professionals [4][10] [12].

As a consequence, to perform suitable development, the usability test examined two indicators for providing effective functioning with regard to self-monitoring, realtime feedback, and patient involvement in diabetes treatments. Thus, type- 2 diabetes functions has been designed, developed, and tested for usability by considering in many aspects where features of the previous developments mentioned above and the 
expected outcomes of the development for supporting type- 2 diabetes patients have been also discussed in prior to the development.

The research questions are as follows: How can the patient be enabled to use the application effectively and what should be functions in mobile application for diabetes?

In this study, the purposes were to (1) analysis, design and develop a T2DM with user involvement in the design, one that involves coordination between doctor and patient; and (2) conduct an application test.

\section{Experimental Procedure}

\section{$2.1 \quad$ Research methods}

In order to facilitate the description of research participation in this study, the research has been divided into four steps. Fig. 1 illustrates the framework for developing the T2DM self-management via mobile application.

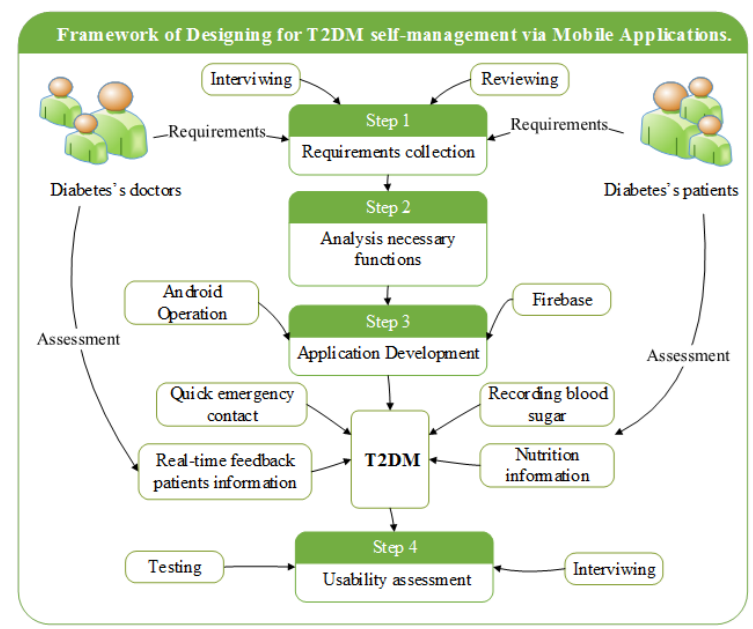

Fig. 1. Framework for developing the T2DM.

Step 1: Requirements collection: this step includes the involvement of the experts from Maharaj Nakorn Chiang Mai Hospital in the Section of Endocrinology and Metabolism, Department of Internal Medicine, Faculty of Medicine; Faculty of Nursing; and the College of Arts, Media, and Technology, Chiang Mai University presenting the blue print of the application requirements. The necessary information for this step were collected from five experts including doctors and nurses, five diabetes patients and persons related to diabetes patients for application functional requirements. 
Step 2: The functions necessary for supporting diabetes treatment have been analyzed using the information from Step 1 . They are collected as necessary functions for the design based on the lack of performance treatment and by following literature reviews.

Step 3: Android Studio, an official IDE tool and Firebase, a NoSQL cloud real-time database were used as development tools for android operation system.

Step 4: The focus was on usability assessment testing. The step includes the evaluation of performances by applying testing methods for testing GUI, function usability, and user confidence. There were three sample groups of users including professionals, which were doctors and nurses from the Hospital, persons related to diabetes persons, and diabetes patients from the Diabetes Unit from the Faculty of Medicine were asked to test the application.

\subsection{Application taxonomy}

To understand diabetes mobile application taxonomy for self-management, the review in [19] over 1,559 applications from the App Store and Google Play were taken into consideration. The functions of the application can be classified by preliminary taxonomy of apps for diabetes self-management into three components. This is based on the functional modules that work in diabetes application as discussed in many literature reviews[17][26] [27] [28][29][30].

For functional module: This module includes recording the self-monitoring; recording the activities, dilates, and weight; feedback alert; reminder to take medications; nutrition management; insulin calculator; and medication.

For general education module: This module includes display of data in a structured way, instructions on nutrition facts information, and education regarding diabetes information.

For communication module: This module includes involving users to the treatment, communicating with the doctor, real-time interactions and data transmission, data representation, telephone coaching, and social networking.

With regard to the above-mentioned functionality, the T2DM was developed based on reviews and analysis functions, which is illustrated in Fig. 1.

\subsection{Application development testing}

Mobile application testing is a very important point because the development of mobile applications is different from other ordinary applications such as web applications or other traditional websites [22]. It requires a different approach to ensure application quality and reliability, to build high quality applications and to make the software reliable.

There are several usability models available for mobile application testing. According to [23], usability testing is a technique that presents application performance, 
which is devided into five elements: efficiency, satisfaction, learnability, memorability, and errors. There is another testing technique called the People at the Center of Mobile Application Development (PACMAD), which combines two additional attributes: effectiveness and cognitive load and also identifies three aspects that effect a mobile application usability including user, task and context of use [13]. This research employed the PACMAD as a tool for usability testing for the mobile application development.

The testing criterions were design by including five rating scales as the following, and then the analysis has been carried out:

Part 1: Graphic user interface criteria

- Press buttons on the screen which are easy to use

- There is clear distinction of the screen between foreground and background

- The screen colors are appropriately designed

- Each image of the menu communicates with the user effectively

- The number of menu items is suitable and easy to use

- The font size is suitable for the screen and easy to read

- Textured wallpapers are suitable

- The proportion of display areas is appropriate

- The contrast of the display screen is beautiful

- The alignment of the graphics and symbols is easy to understand

Part 2: Function usability criteria

- The application is intuitive and understandable for users on the trial

- The application provides useful information on medication for primary selftreatment

- The medication notification function is useful for treatment

- The blood sugar recording function is easy to use and helps to motivate users to save their data to the app

- The summary of blood sugar readings recorded in the app is useful to the treatment team to plan treatment courses for regulating the patient's blood sugar

- The map function for demonstrating hospitals and nearby agency locations provides emergency contact information

- The phone contact function helps facilitate diabetes treatments

- Transmission of patient information via email to the treatment team is useful for planning treatment courses

- The nutrition information on the app helps users to plan for diabetes treatment

- The diabetes treatment information is useful for the treatment

Part 3: User confidence criteria

- The user will use information from the app for nutrition planning 
- The user will record the sugar level for his/her own benefit in treatment planning and use it for treatment planning

- The user believes that the nutrition information received from the app will help him/her in planning a personalized diet plan correctly

- The user believes that the information from the app will help him/her in planning the treatment correctly

- The user believes that the suggestions given by the app do no harm to users

- The user believes that using the app can reduce personal health expenditure

- The application makes type 2 diabetes treatment easier

- The user believes that using the app will help in motivating users toward type 2 diabetes self-caring

- The user agrees with the application usage and will suggest to his/her friends to use the same information

- The user will definitely download the application and recommend it to others

Table 1. List of Patients' Notes and Doctors' Suggestions

\begin{tabular}{|l|l|l|}
\hline \multicolumn{2}{|c|}{ Poctors } & \multicolumn{1}{c|}{ Issue Discussion } \\
\cline { 1 - 2 } $\begin{array}{l}\text { Found that patients always miss } \\
\text { recording of weight, nutrition, } \\
\text { etc., which causes difficulties in } \\
\text { the medical treatment plan. }\end{array}$ & $\begin{array}{l}\text { Loss of information, forgot to } \\
\text { record the information to report } \\
\text { to the doctor. }\end{array}$ & $\begin{array}{l}\text { Need a recording function for } \\
\text { demographic information on the } \\
\text { patient. }\end{array}$ \\
\hline $\begin{array}{l}\text { Found that patients provide } \\
\text { results of low outcome of } \\
\text { treatment. }\end{array}$ & $\begin{array}{l}\text { Forgot to take medicine. } \\
\text { - No plan, or uncontrolled } \\
\text { nutrition. } \\
\text { - Cannot understand which type } \\
\text { of medicine to eat with each } \\
\text { meal. }\end{array}$ & $\begin{array}{l}\text { Need a recording function / } \\
\text { information. }\end{array}$ \\
\hline $\begin{array}{l}\text { Found that there is a trend of } \\
\text { patients losing information } \\
\text { regarding their sugar levels. }\end{array}$ & $\begin{array}{l}\text { - Forgot to record the sugar } \\
\text { level every day. }\end{array}$ & $\begin{array}{l}\text { Need a recording function to } \\
\text { record sugar levels. }\end{array}$ \\
\hline $\begin{array}{l}\text { Found that patients do not have } \\
\text { exact information regarding the } \\
\text { diagnosis during meeting the } \\
\text { patients in each round meeting. }\end{array}$ & $\begin{array}{l}\text { - Lost contact with the doctor on } \\
\text { leaving for home. }\end{array}$ & $\begin{array}{l}\text { Need a communication function } \\
\text { or the facility to export patient } \\
\text { information before meeting the } \\
\text { doctor in each round meeting. }\end{array}$ \\
\hline
\end{tabular}

\subsection{Designing diabetes mobile application}

The diabetes mobile application, T2DM has been designed by taking the theoretical method of "design thinking" which adopts a human-centered approach to the designing [20] [11]. The functionality of the application was analyzed from the viewpoint of the needs of patients and doctors who monitor the patient. The involvement of both doctors and patients and the cooperation between in modern health care system 
as reviewed from recent research studies were analyzed and the result leads to the prototyping and designing of the first mobile application.

Waterfall methodology was employed for the development by using the functional requirements from the involvement. The objective was to identify the appreciated functions and the challenges. Table 1. illustrates issues regarding the involvement of the patients and the doctor's suggestions.

The T2DM has been investigated for feasibility regarding functional requirements and considered appropriate for use for diabetes patients. Then, the doctors made the final decision after analyzing which functions are appropriated for the use. Fig 1 illustrates the state diagram as the blueprint for the T2DM mobile application, which has been developed on the Android operating system. Fig. 1 contains four functionalities, which correspond to the functions in Table 1. The states in Fig 1 include the designing of the T2DM, which designed to support online operation mode. In terms of consistency, up-to-date information about nutrition facts of common Thai foods and phone numbers are pieces of information that doctors of diabetes are concerned about, as they need to know the amount of nutrition obtained by the patients in their daily lives. The website Firebase.google.com was applied as the Backend-as-a-Service (BaaS), and it provides a simple technique to save the binary files that are used for database management of nutrition and information regarding the phone number.

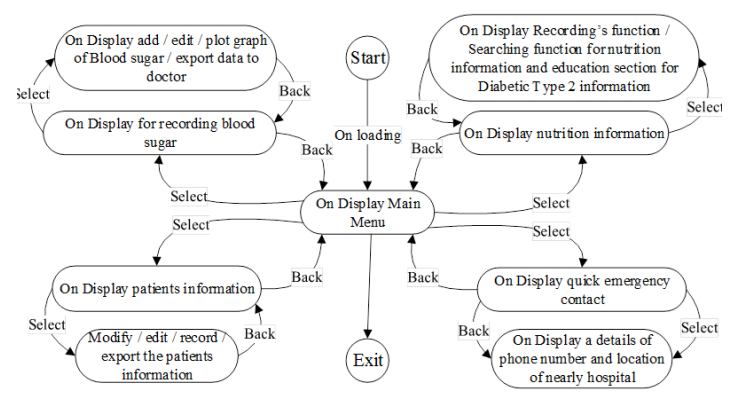

Fig. 2. State diagram for T2DM mobile application development

\subsection{Application development functions}

The objective was to support clinical treatment of type 2 diabetes via a mobile application. Fig. 3 shows a screenshot of the main menu where the middle panel is the logging-in function for users via google accounts, whereas the right panel shows the application main menu. The left panel in Fig. 4 shows the recording function of blood sugar, which is indicated by the calendar display view. A text box on this screen is for entering blood sugar level by user. The right panel in Fig. 4 shows a bar chart represents blood sugar levels. 


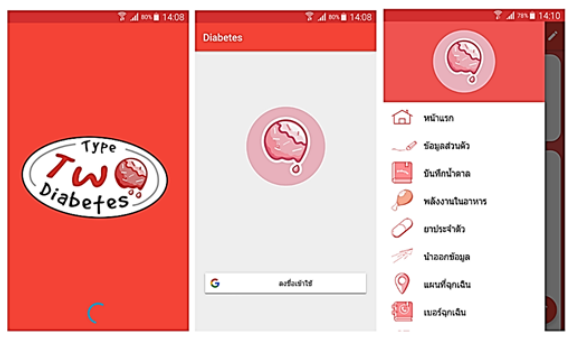

Fig. 3. The application screens of the main function which need to be logged in via a google account.

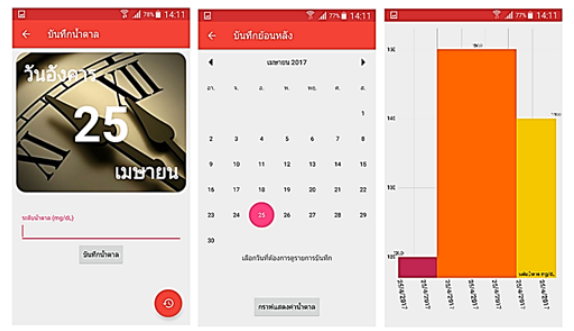

Fig. 4. The application screens of the blood sugar recording function which contains the retrieving history of the blood sugar order by day and month, in addition to the bar chart data visualization.

Fig. 5 illustrates a list of common Thai foods, which classified into four categories including food, drink, dessert and fruit. Each of the food items contains nutrition facts information such as the carbohydrate amount (grams) and energy units (calories). This function allows users to calculate the amount of carbohydrates and the calories in each meal and record the information for treatment planning when consulting with their doctor. The objective is to improve the outcome of the treatment plan, allow diabetologists to nutritional coach, and provide indirect information and education about food nutrition facts especially the carbohydrate amount for diabetes patients.

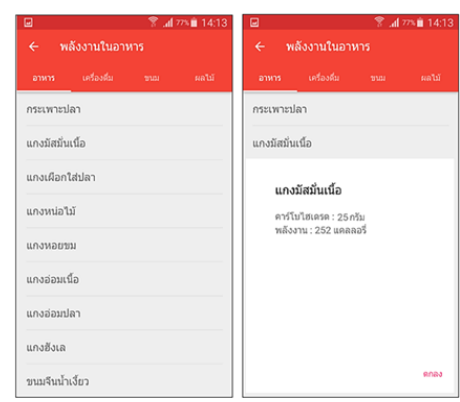

Fig. 5. The application screens of the nutrition function, which contains a list of common Thai foods and nutrition facts information of each food item. 
Fig. 6 shows the application function for improving the treatment outcome by reminding patients to take medicines. The function for recording the list of medicines when the diabetologist prescribes them for patients was used to prevent the patient from forgetting to take them. Fig. 7 demonstrates the function that transfers patients' information via direct email to their doctors. The sending packet covers the blood sugar level as well. Fig. 8 displays the emergency call function, which used for recording contact persons when the patient needs help. It will also show the contact phone number of the hospital nearby.

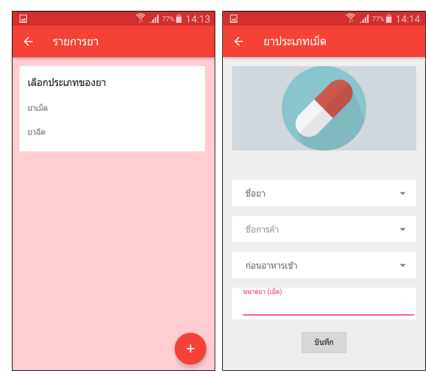

Fig. 6. The application screens of the function of recording medical information.

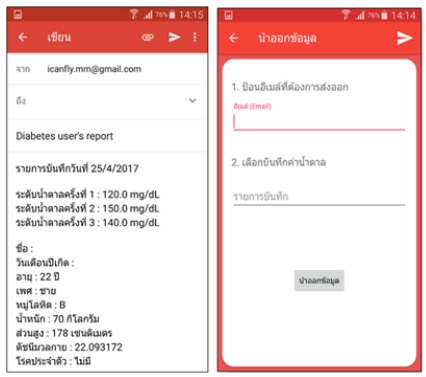

Fig. 7. The application screens of the function for reporting patient information regarding blood sugar to the diabetologist via email exportation.

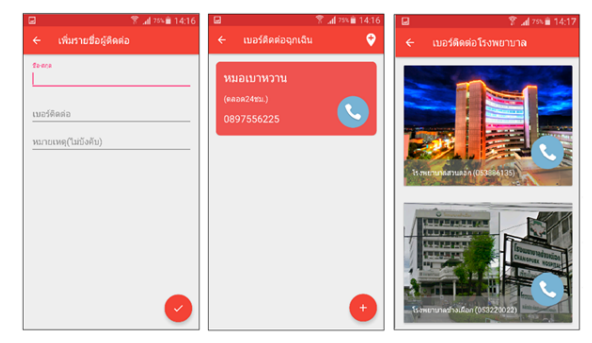

Fig. 8. The left panel shows the function of adding contact persons, the middle panel shows the list of contact persons, and the right panel shows the nearby hospital contacts. 


\subsection{Results}

The results of the test with regard to the technical functions of the T2DM were collected from participant observation during the period from January 10, 2018, to January 30,2018 . The testing aimed to review the functional capacity in terms of using the application in real-life situations by diabetes patients. Fig. 9 includes the first part of the data collection which contains 11 general investigation criteria which shows varied demographic characteristics of all respondents. The majority of the respondents were female $(65.5 \%$ female, $35.5 \%$ male). Where $64.24 \%$ of the respondents belonged to the doctor-nurse group, $22.45 \%$ made up persons related to diabetes patients and $13.31 \%$ was the percentage of diabetes patients. The age range of the respondents is concerned; the data shows that the largest proportion of the respondents were between the ages of 31-35. With regard to the education of the respondents, receipt of a Bachelor's degree was the most common educational attainment of the respondents.

Regarding the mobile operation used by the respondents, android held the highest proportion with $62.42 \%$, at the same time, the group of persons related to diabetes patients was the group that had the highest proportion of respondents using this operation. To a query regarding using smartphones for finding information, persons related to diabetes patients and diabetes patients, with high proportions at $97.56 \%$ was claimed that they use smartphones for finding information, whereas, only $2.44 \%$ of the respondents responded that they never used smartphones for finding information. The majority of the respondents usually spend time more than 3 hours a day using mobile phones: both the persons related to diabetes patients and the diabetes patients registered high proportions.

When the respondents were queried about the knowledge of mobile applications for health information, $62.17 \%$ answered that they knew about applications before, whereas $37.83 \%$ answered that they never known about it. In addition, 54.79\% had already installed at least a healthcare application on their mobile phones where $45.21 \%$ never installed. $65.48 \%$ paid for the application, and the majority were the doctor-nurse group. Regarding their knowledge about diabetes mobile applications, the group of doctors and nurses responded positively that they know such applications, with a high proportion, of $59.48 \%$, whereas persons related to diabetes patients and diabetes patients responded negatively that they did not know, with a high proportion of $40.52 \%$. 

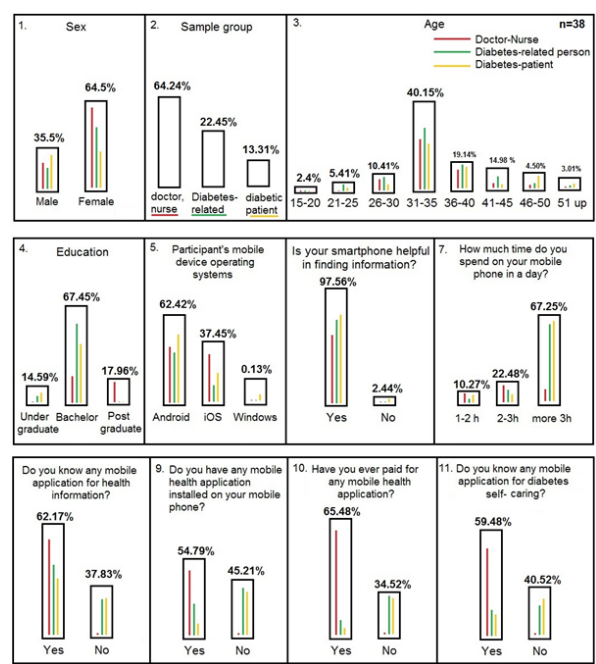

Fig. 9. The result of general questions put forward to the respondents in order to obtain the response as user information.
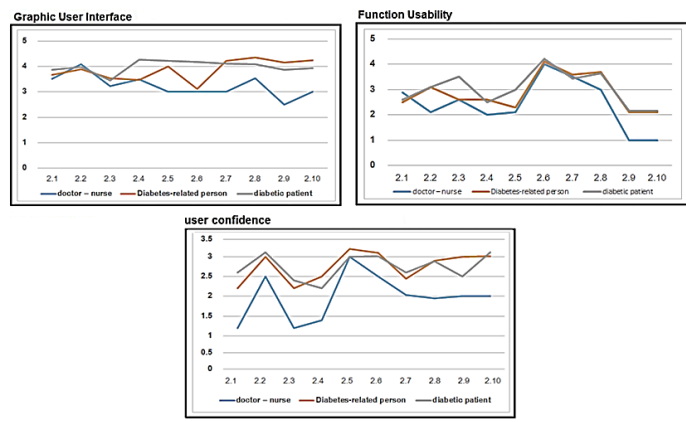

Fig. 10. The result of the application test, which corresponds to section 2.3, which is the application development testing section.

The T2DM development were tested for successful measurement using a five rating scale evaluation survey; then, the mean score of each question and respondent group were summarized.

Fig. 10 demonstrates the results of the criteria application testing which included three parts corresponding to the application development testing discussed in section 2.3 .

The first part focused on the graphic user interface, specifically on the point that the contrast of the display screens need to be improved as revealed by the responses from the doctor-nurse group. The doctor-nurse group has scored different from the other groups did. They gave the reason that improving display screen contrast could make the application simpler and more visible. More criteria are useful for development where the scores of the evaluation are higher than 3.00 in average 
The second part takes into consideration for function usability; it was found that from the summary of requirements, the functions that received encouragement from all the groups, regarding the usage of the function, were map function, phone contact function, and transmitting of patient information to the doctor function. However, the nutrition information function was concerned seriously to all the groups, as the application could not provide correct information such as local food information, unit of measurement for carbohydrates, etc.

Part 3 focused on user confidence of the T2DM. The results show that the doctornurse group had a lower score than the other groups, whereas persons related to diabetes patients and diabetes patients agreed with similar confidence trends in all the criteria. As already seen, the nutrition planning function was unable to provide useful information. While, having accurate nutrition information would significantly affect users' beliefs and convictions as the doctor-nurse group agrees to suggest to other people to use this application.

\subsection{Discussion}

In this study, a mobile application for type 2 diabetes was developed by using user involvement by including users such as doctors and nurses, persons related to diabetes patients, and diabetes patients; this was for analyzing and designing the T2DM functions. Five medical school experts, diabetes-patients, and persons related to diabetes patients were selected for investigating their requirements together with consideration of the recently conducted research studies to specifically identify what functions are suitable and necessary for the T2DM. The development of the application followed the application taxonomy for diabetes self-management, and the learning tool was designed by following the studies of [17][26][27][28][29][30]. The human-centered theory with reference to GUI were employed for user-friendly GUI design [11] [20].

According to literature reviews, although, there are many necessary functions for diabetes mobile application developing, the proposed development of the application included only the real functional requirements of users and experts. In this study, the T2DM focused on four main functions including blood sugar function, nutrition function, patient information function, and emergency contact function.

There have been many researchers claimed that mobile applications can be used as a tool for managing patients' health, self-management interventions, and real-time feedback in diabetes patients [3][6][14][16][21]. For the analysis step, the T2DM has been developed by following the same framework under Thai context.

After the development was completed, testing started. There were 38 users including doctors, nurses, and diabetes patients were asked to test the features of the application such as the application GUI, function usability, and user confidence.

When considering the testing criteria Part 1, the test for GUI, it shows that the satisfactory scores from the doctor-nurse group was lower than the other groups. From the low score point, it is evident that the contrast of the display screen is considered as 
providing poor visibility. This issue needs to be addressed and improved in the next development.

When considering the testing criteria Part 2, which includes the function usability test, the doctor-nurse group had serious concerns in every criterions excluding the criterion discussed in section 2.2. Although, the T2DM offers all the important functions, and the researchers claim that their application's functions are powerful and effective enough for use by diabetes patients, the result reveals that the group of doctors and nurses gave lower scores than the other groups did.

The question to be addressed is why the doctor-nurse group did reflect poor acceptance. When considering each criterion, it has been found that in-depth information from the doctor-nurse group reveals that as far as context of the use is concerned, the criterion may not be applicable to general people. This is because, in the application, some functions have to be carried out manually which, in turn, it will provide general understanding and literacy regarding information on diabetes. This would increase the diabetes self-care knowledge for patients such as how to record blood sugar and how to calculate sugar levels, and etc.

Moreover, everybody who uses this application should gain some experience and literacy regarding using IT health applications. This corresponds to the result given in the general questions section, items 8-11, in Fig. 9, where the proportion of persons related to diabetes patients and diabetes patients has a lower score in the perception of using mobile applications for diabetes. Although, the common academic level of the respondents was a Bachelor's degree, IT literacy and diabetes knowledge of the user can affect the usability of the application. Hence, the mobile application design for diabetes should consider the users' appropriation and contents by the suggestion of [23].

Furthermore, regarding to the nutrition function of the T2DM, the doctor-nurse group suggested that this part is a necessary function which could help diabetes patients and persons related to diabetes patients to calculate the carbohydrate amount in their meals; this part has been concerned by following researchers Adam, P. in [7], Petersen, M., and Hempler, N. F. in [11] for example.

In this development, it has been found that the application may not contain accurate information especially information on local food nutrition levels and some of the meal information may not provide information on the carbohydrate levels. This function is extremely important for diabetes treatment because the T2DM is also aimed to be a learning tool as well as a tool for self-monitoring.

In addition, in the development of this application, with regard to real requirements from stakeholders, it has been found that communication function is also an important function for doctors and patients for exchanging the patient data obtained from the self-monitoring. Additionally, map function and phone contact function are also useful functions, since they could help patients in the search for facilitation of treatment. 
These functions corresponds to several studies [7][11]. The application is different from many applications in the app market [17]

When considering part 3, which consists of user confidence, the result obtained from diabetes patients and diabetes patients' related persons reveals that they agreed to apply the T2DM in their treatment as tools for helping them. However, when it comes to the question of confidence regarding accurate nutrition information provided by the T2DM, the result shows that there was a lack of confidence in the application performance, which is a result similar to the result shown in step 2. To develop a useful diabetes application, the factor of nutrition function should be the first priority to concern.

Consequently, in the T2DM, while some functions can perform well from the evaluation, some are poor, based on this case development report. At least, the benefits of the T2DM are because of the fact that it has been developed using the procedure for role model development from an understanding of the requirements through involvement of real medical professionals and groups of patients and patients' relatives.

The T2DM application can be further developed and its performance can be increased by improving the nutrition information in the nutrition function. Additionally, the part of the learning function for learning about diabetes information should be also developed.

\subsection{Conclusion}

In this study, the purpose was to analyze, design, develop, and test the T2DM with user involvement between stakeholders including diabetes professionals and diabetes patients and their relatives. This case development report presents the results of the development. The analyzed necessary functions have been developed, which also revealed the functions that are actually necessary for the T2DM.

The most effective application development of the T2DM started by developing the functions that are necessary obtained through stakeholders involvement and requirements analysis. Stakeholders include real users such as diabetes patients and persons related to diabetes patients as well as medical professionals. The result of the application testing was satisfactory but not in the functional cases.

The study found that functions of communication in the T2DM such as maps, phone contacts, and patient information interchanging are necessary basic functions for supporting users. Nevertheless, blood sugar recording and data visualization are also necessary basic functions, whereas the nutrition function is a seriously concerned function, which should be considered in the next development of diabetes applications. 


\subsection{Ethical Consideration}

The surveys of this study were carried out on human subjects who agreed to participate regarding the preliminary design of the application. The study was conducted regarding compliance with IRB requirements for NONE 256005015 approved from the IRB board of the Faculty of Medicine, Chiang Mai university.

\section{Acknowledgement}

This research was funded by the College of Arts, Media and Technology, Chiang Mai University. Cooperative research and the development of the T2DM were carried out with the collaboration between the Faculty of Pharmacy; Faculty of Medicine; Faculty of Nursing; and the Embedded Systems and Mobile Application Laboratory, the College of Arts, Media, and Technology, Chiang Mai University.

\section{References}

[1] NCD Risk Factor Collaboration (2016). Worldwide trends in diabetes since 1980: a pooled analysis of 751 population-based studies with 4.4 million participants. The Lancet. Vol. 387(10027): 1513-1530. https://doi.org/10.1016/S0140-6736(16)00618-8

[2] Lisa-Maria, G.H., Iren Boren, Inaki, G., Josef, N., and Mirjam, L. (2015). Design and Developing a Mobile Smartphone Application for Women with Gestational Diabetes Mellitus Followed-Up at Diabetes Outpatient Clinics in Norway. Healthcare. Vol. 3, 310-323. https://doi.org/10.3390/healthcare3020310

[3] T.C. Skinner, M.E. Carey, S. Cradock, H. Daly, M.J. Davies, Y. Doherty, et al., Diabetes education and self-management for ongoing and newly diagnosed (DESMOND): process modelling of pilot study, Patient Educ. Couns. 64 (1-3) (2006), 369-377. https://doi.org/10.1016/j.pec.2006.04.007

[4] Shivani Goyal, Plinio Morita, Gary F. Lewis, Catherine Yu, Emily Seto. Joseph A. Cafazzo. (2016). The Systematic Design of a Behavioural Mobile Health Application for the SelfManagement of Type 2 Diabetes. Canadian Journal of Diabetes. 40 (2016) 95-104 https://doi.org/10.1016/j.jcjd.2015.06.007

[5] Charlene, C., Kaitlin, G., Jenine, K., Amy, M., Madeleine, S., Maggie, F., and Matthew, K. (2015). Evaluating Diabetes Mobile Applications for Health Literate Designs and Functionality. Centers for Disease Control and Prevention. 12, 2-13

[6] Eirik, A., Dag, H.F., Stein, O. S., Taridzo, C., Naoe, T., Gunnar, H., and James T. T. (2012). Mobile Health Applications to Assist Patients with Diabetes: Lessons Learned and Design Implications. Journal of Diabetes Science and Technology. Vol. 6(5):1197-1206. https://doi.org/10.1177/193229681200600525

[7] Adam P. (2014). Improving Type 1 Diabetes Management With Mobile Tools: A Systematic Review. Journal of Diabetes Science and Technology. Vol. 8(4):859-864. https://doi.org/10.1177/1932296814529885 
Paper-Type 2 Diabetes Mobile Application for Supporting for Clinical Treatment...

[8] Yun Ahn, Jeahurn Bae, Hee-Seon Kim. (2016). The development of a mobile u-Health program and evaluation for self-diet management for diabetic patients. Nutrition Research and Practice. Vol. 10(3):342-351. https://doi.org/10.4162/nrp.2016.10.3.342

[9] Robert J. A. (2010). Improving health outcomes with better patient understanding and education. Risk Management and Healthcare Policy. Vol. 3:61-72.

[10] Omar El-Gayar, Prem Timsina., Nevine Nawar, and Wael Eid., (2013). Mobile Applications for Diabetes Self-Management: Status and Potential. Journal of Diabetes Science and Technology. Vol. 7(1):247-262. https://doi.org/10.1177/193229681300700130

[11] Petersen, M., and Hempler, M. F. (2017). Development and testing of a mobile application to support diabetes self-management for people with newly diagnosed type 2 diabetes: a design thinking case study. BMC Medical Informatics and Decision Making. Vol.17:1-10.

[12] Helen Fu, Siobhan K. McMahon, Cynthia R. Gross, Terrence J. Adam., Jean F. Wyman. (2017). Usability and clinical efficacy of diabetes mobile applications for adults with type 2 diabetes: A systematic review. Diabetes Research and Clinical Practice. Volume 131, 70-81. https://doi.org/10.1016/j.diabres.2017.06.016

[13] Harrison, R., Derek F., and David D. (2013). Usability of mobile applications: literature review and rationale for a new usability model. Journal of Interaction Science. 2013, 1:1. https://doi.org/10.1186/2194-0827-1-1

[14] Chavez, S., David, F., Yi, G., Angelina, B., Smith, M., Jennifer, W., and François, M. (2017). Mobile Apps for the Management of Diabetes. Diabetes Care. Vol. 40(10). https://doi.org/10.2337/dc17-0853

[15] Chenchen, G., Lanshu., Z., Zhihui, L., Wang., H., Bowers, B. (2017). Mobile application for diabetes self-management in China: Do they fit for older adults?. International Journal of Medical Informatics. Vol. 101, 68-74. https://doi.org/10.1016/j.ijmedinf.2017.02.005

[16] Kim, Y. J., Rhee, S. Y., Byun, J. K., Park, S. Y., Hong, S. M., Chin, S. O., Woo, J., Kim, S. K., and Kim, Y. S. (2015). A Smartphone Application Significantly Improved Diabetes Self Care Activities with High User Satisfaction. Diabetes and Metabolism Journal. Vol.39: 207 217. https://doi.org/10.4093/dmj.2015.39.3.207

[17] Istepanian, R. S. (2015). Mobile applications for diabetes management: efficacy issues and regulatory challenges. Lancet Diabetes Endocrinol. Vol, 3(12):921-3. https://doi.org/10.1016/S2213-8587(15)00414-3

[18] Powell AC, Landman AB, Bates DW. (2014). In search of a few good apps. JAMA. 2014 May 14:311(18):1851-2. https://doi.org/10.1001/jama.2014.2564

[19] Spyros, K., (2017). Mobile App-Based Interventions to Support Diabetes Self-Management: A Systematic Review of Randomized Controlled Trials to Identify Functions Associated with Glycemic Efficacy. JMIR Mhealth Uhealth. 5(3): e35. https://doi.org/10.2196/mhealth.6522

[20] Brown. T., and Wyatt, J. (2010). Design Thinking for Social Innovation. Stanford Social Innovation Review. Stanford University. Online: https://ssir.org/articl es/entry/design thinking for social innovation

[21] Goya, S., Morita, P., Lewis, G., Yu, C., Seto, E., and Acfazzo, J. (2016).

[22] Samer Z., Norsaremah S., and John G. (2016). A systematic mapping study of mobile application testing techniques. The Journal of Systems and Software. 117: 334-356. https://doi.org/10.1016/j.jss.2016.03.065

[23] Nielsen, J., and Budiu, R. (2012) Mobile Usability, Berkeley CA: New Riders Press. 
[24] Mill, A., Schmied, V.A. and DHLEM, H.G. (2013). Get alongside us, women's experiences of being overweight and pregnant in Sydney, Australia. Maternal \& Child Nutrition. 9, 309 321. https://doi.org/10.1111/j.1740-8709.2011.00386.x

[25] Carolan, M., Steele, C., Margetts, H. (2010). Knowledge of gestational diabetes among health-workers in cross-cultural patient encounter around dietary advice. Midwifery. 26(6). 579-588. https://doi.org/10.1016/j.midw.2009.01.006

[26] Danes M, and Whinder F. (2013). Diabetes management goes digital. Lancet Diabetes Endocrinol. 2013 Sep; 1(1):17-8. https://doi.org/10.1016/S2213-8587(13)70100-1

[27] American Diabetes Association. (2017). Standards of medical care in diabetes-2017. Diabetes Care. Journal of Clinical and Applied Research and Education. 40: 15-34.

[28] De, R.M., Kim J, Jing Y, Khadra M, Nanan R. (2016). A systematic review on incentivedriven mobile health technology: As used in diabetes management. Journal of Telemedicine and Telecare. 23(1): 26-35.

[29] Basilico A, Marceglia S, Bonacina S, Pinciroli F. (2016).Advising patients on selecting trustful apps for diabetes self-care. Computers in Biology and Medicine. 1 (71):86-96. https://doi.org/10.1016/j.compbiomed.2016.02.005

[30] Yuan, Wu., Xun Yao, Giacomo Vespasiani, Antonio Nicolucci, Yajie Dong, Joey Kwong, Ling Li, Xin Sun, Haoming Tian, and Sheyu Li. (2017). Mobile App-Based Interventions to Support Diabetes Self-Management: A Systematic Review of Randomized Controlled Trials to Identify Functions Associated with Glycemic Efficacy. 5(3): 1-18.

\section{Authors}

Orawit Thinnukool (corresponding author) is an Assistant professor and has received his Ph.D. Degree in Research Methodology. His background is in information technology, education technology and research operation. He works in the Department of Modern Management and Information Technology at Collage of Art, Media and Technology, Chiang Mai University.

Pattaraporn Khuwuthyakorn received her Ph.D. in Engineering from the Australian National University in 2012. Currently, she is a lecturer at the College of Arts, Media and Technology in the Department of Modern Management and Information Technology at Chiang Mai University. (pattaraporn.khuwuth@cmu.ac.th).

Purida Wientong received her Ph.D. in Pharmaceutical Care. Her area is in healthcare system and healthcare management. Currently she is a researcher and a lecturer of the Department of Pharmaceutical Care, Faculty of Pharmacy at Chiang Mai University. (purida.v@cmu.ac.th).

Benjamas Suksati received her Ph.D. from University of North Carolina at Chapel Hill, United States Of America; she now is a staff in the department of Medicine Nursing, Faculty of Nursing, Chiang Mai University. (benjamas.s@cmu.ac.th)

Nipawan Waisayanand is the assistant professor and also as the medical doctor in the section of Endocrinology and Metabolism, Department of Internal Medicine , Faculty of Medicine, at Chiang Mai University (nipawan.w@cmu.ac.th).

Article submitted 29 October 2018. Resubmitted 25 November 2018. Final acceptance 12 December 2018. Final version published as submitted by the authors. 